\title{
Neuroinfections: Presentation, Diagnosis, and Treatment of Meningitis and Encephalitis
}

\author{
Authors: \\ *Kaitlin M. Bowers, ${ }^{1}$ Vishnu V. Mudrakola ${ }^{2}$ \\ 1. Hilton Head Hospital, Hilton Head Island, South Carolina, USA \\ 2. Licking Memorial Hospital, Newark, Ohio, USA \\ *Correspondence to Kaitlin.M.Bowers@gmail.com \\ Disclosure: \\ The authors have declared no conflicts of interest. \\ Received: \\ 11.03 .20 \\ Accepted: \\ 06.05 .20 \\ Keywords: \\ Anti-NMDA receptor encephalitis, bacterial meningitis, encephalitis, herpes simplex \\ virus encephalitis, meningitis, neuroinfections, opportunistic infections. \\ Citation: \\ EMJ Neurol. 2020;8[1]:93-102.
}

\begin{abstract}
Neuroinfections cause significant morbidity, mortality, and long-term disability. These infections rarely present with the classic signs and symptoms taught in textbooks. Due to the similarities in presentation between neuroinfections and many other disease processes, delayed diagnosis is common. Thus, it is important that care providers have a high clinical suspicion for potential cases because early diagnosis and treatment can significantly improve outcomes. This article serves as a review of the approach to a patient with suspected neurological infection with an emphasis on clinical presentation, diagnosis, and treatment of the major causes of meningitis and encephalitis. Additionally, patients in an immunocompromised state are vulnerable to a whole host of additional neuroinfections that present atypically and will also be addressed.
\end{abstract}

\section{INTRODUCTION}

Infections of the central nervous system (CNS) are varied in their causes, presentations, and prognosis. They can be sudden in onset and have the potential to cause significant morbidity and mortality. A particular clinical challenge for CNS infections is the relatively isolated nature of the CNS and its protective mechanisms. The blood-brain barrier is the main protective feature of the CNS and works to restrict the passage of pathogens and large molecules from the bloodstream into the cerebrospinal fluid (CSF). It is composed of a network of specialised brain endothelial cells as well as pericytes and astrocytes that support brain capillaries., ${ }^{1,2}$ A specific challenge that arises as a result of this protective mechanism is the identification of the specific neurovascular space where the infection resides, be it the meninges, the epidural space, or the parenchyma itself. The extent of the neurovascular space involved in infections is often a spectrum extending from the meninges to the encephalon. An infectious agent that initially causes meningitis can easily progress to encephalitis, also known as meningoencephalitis. The extent of disease produced by a specific agent can also vary drastically between patients.

This article is a review on the initial approach to a patient with suspected neurological infection with emphasis on clinical presentation, diagnosis, and treatment of meningitis and encephalitis. 


\section{MENINGITIS}

The meninges are a triple-layer membranous envelope composed of the pia mater, dura mater, and arachnoid space. Meningitis refers to inflammation of the leptomeninges and CSF within the subarachnoid space that exists between the pia mater and the arachnoid layers. ${ }^{3}$ The exact cause of the inflammation, however, can vary. There is a myriad of infectious and noninfectious causes of meningitis, but for the purpose of this review, the focus will be acute infections of the meninges. Primary infectious causes include bacterial, viral, and fungal origins.

Meningitis secondary to a bacterial infection can cause significant morbidity and mortality as a result of the severe inflammation. The inflammation can cause significant oedema of the surrounding structures and increased intracranial pressure. ${ }^{4}$ Many organisms, such as Escherichia coli and Neisseria meningitidis, are pyogenic and can cause a thick suppurative exudate that covers the brainstem and thickens the leptomeninges. ${ }^{3}$ The main pathogenic bacteria implicated in meningitis varies by age and degree of immunocompromise. The most common causes of meningitis in neonates are Streptococcus agalactiae and E. coli. Whereas in children beyond the neonatal period, the most common agents are N. meningitidis and Streptococcus pneumoniae. ${ }^{5}$ Common agents in adults include $N$. meningitidis and S. pneumoniae, but Listeria monocytogenes must also be considered, particularly in the elderly.

Another important pathogen to consider is Haemophilus influenzae type b (Hib). Widespread vaccination has significantly decreased the incidence of Hib meningitis by over $90 \%$ in some countries. ${ }^{6,7}$ However, it remains a prevalent pathogen in underdeveloped and unvaccinated populations. Hib can cause severe bacterial meningitis in children with significant morbidity. Up to $20 \%$ of children that recover from Hib meningitis experience long-term neurological sequelae such as sensorineural hearing loss, developmental delay, seizures, and hydrocephalus. ${ }^{8}$ Hib can also cause significant disease in immunocompromised and asplenic patients at any age.

Viral meningitis is usually less clinically severe than bacterial meningitis. Herpes simplex virus (HSV) and varicella-zoster virus (VZV) are two

main examples of neurotropic viruses that can frequently cause disease. HSV-1 infection can cause severe encephalitis in adults whereas in children, HSV-2 tends to cause more serious infections. However, incidental and non-neurotropic viruses account for the majority of viral meningitis cases. Nonpolio enteroviruses account for more than $85 \%$ of all cases of viral meningitis. ${ }^{9}$

\section{Clinical Presentation}

Meningitis must be considered in any patient presenting with fever and headache. Diagnosis is complicated by the fact that the full triad of fever, nuchal rigidity, and meningismus is rarely present. A thorough history and physical exam to rule out other common aetiologies is paramount. Establishing pretest probability is important because the gold standard to diagnose meningitis, lumbar puncture (LP), and CSF culture, is an invasive and skilful procedure that can be difficult to perform under certain circumstances. Common historical features of patients with meningitis include headache, vomiting, and neck pain. ${ }^{10}$ The presence of these symptoms alone has poor sensitivity, with the pooled sensitivity for headache being 50\% (95\% confidence interval: 32-68\%) and 30\% for nausea/vomiting (95\% confidence interval: 22-38\%). ${ }^{10}$ However, the absence of fever, neck stiffness, and altered mental status effectively eliminates meningitis. ${ }^{10}$ As far as physical signs are concerned, Kernig's and Brudzinski's signs were both described in the late 1800s and early 1900s, respectively. Most of the patients they studied had significant meningeal inflammation with underlying Mycobacterium tuberculosis and S. pneumoniae infections. "Multiple recent studies have shown poor sensitivity of these signs, even in the presence of jolt accentuation. 12,13 Despite poor sensitivity, these signs are quite specific (9295\%) for pleocytosis, which again demonstrates the importance of a detailed exam. Overall, clinical gestalt is the best guiding feature in pursuing a workup of meningitis and establishing the diagnosis.

\section{Diagnosis}

The hallmark diagnostic procedure for meningitis is LP. Serum laboratory markers can indicate overall presence of inflammation, but none can specifically diagnose meningitis. The specific technique and contraindications of the procedure 
will not be discussed here, but it is important to note that the technique is invasive and that proper equipment along with patient positioning are vital to the success of the procedure. There has also been much discussion as to whether a noncontrast CT scan of the brain is necessary prior to performing the procedure because of the fear of underlying mass effect and increased risk of herniation with a LP. While one would think that head CT prior to LP is relatively harmless, obtaining a head CT when not indicated can delay definitive diagnosis and most importantly treatment of acute meningitis. In a recent study, Michael et al. ${ }^{14}$ noted that unnecessary head CT caused significant delays in performing LP and thus decreased the utility of CSF culture in instances where antibiotics had already been started. There are specific clinical criteria for when head CT should precede LP. Per European Society of Clinical Microbiology and Infectious Diseases (ESCMID) guidelines, these are a Glasgow coma score $<10$ and focal neurological deficits other than cranial nerve palsies. ${ }^{5}$ Based on the available data, in the absence of these clinical findings, it is safe to perform the LP without a preceding head CT.

The presence of increased cell counts in the CSF is known as pleocytosis and is strongly indicative of meningeal inflammation. The leukocyte differential can further hint towards the aetiology. Viral aetiologies tend to generate a lymphocytic predominance, whereas bacterial aetiologies generate a neutrophilic predominance. These trends and patterns in the cell count and differential are still nonspecific, but there are data suggesting that marked pleocytosis in itself is sensitive for bacterial meningitis. Agueda et al. $^{15}$ noted a cutoff value of 321 white blood cells/ $\mu \mathrm{L}$ showed the best combination of sensitivity (80.6\%) and specificity (81.4\%) for the diagnosis of bacterial meningitis in a recent paediatric, retrospective study. The first reported measurements from CSF analysis are usually the CSF protein and glucose levels. While not diagnostic, trends in protein and glucose levels can hint towards whether the infectious cause is viral, bacterial, or fungal (Table 1).

The gold standard for diagnosis remains as CSF culture for identification of the pathogen. Culture results are diagnostic in $70-85 \%$ of cases prior to antibiotic exposure. Sensitivity decreases by $20 \%$ following antibiotic pretreatment. ${ }^{16}$ However, cultures are time-consuming, and patients are often started on empiric treatment well before culture data results. A novel method for identifying the pathogen is through gene identification via PCR. PCR methods allow for rapid pathogen identification through amplification and matching of the pathogen's gene products. ${ }^{17}$ This technology has evolved into multiplex PCR which allows for identification of multiple nucleic acid targets within a single reaction. This technology is rapid, sensitive, and specific. A recent multicentre, prospective study on $>1,500$ specimens by Leber et al. $^{18}$ revealed that the sensitivity and specificity of this method was well above $90 \%$ for the most common pathogens implicated in meningitis. Many institutions have adopted such a filmarray panel. Rapid identification of pathogens is important because it can decrease duration of antibiotic therapy and duration of hospitalisation. ${ }^{19,20}$

Table 1: Typical cerebrospinal fluid profiles for bacterial, viral, and fungal meningitis.

\begin{tabular}{|l|l|l|l|}
\hline & Bacterial & Viral & Fungal \\
\hline Opening pressure & Increased & Normal & Increased \\
\hline Appearance & Cloudy to purulent & Clear & Clear or cloudy \\
\hline CSF WBC & Raised & Raised & Raised \\
\hline Differential & Neutrophilic & Lymphocytic & Lymphocytic \\
\hline CSF protein & Increased & Mild increase & Increased \\
\hline CSF glucose & Decreased & Normal-to-mild decrease & Mild decrease \\
\hline
\end{tabular}

CSF: cerebrospinal fluid; WBC: white blood cell. 
Table 2: Guidelines for empiric antibiotics for suspected bacterial meningitis based on age and common pathogens. ${ }^{5}$

\begin{tabular}{|c|c|c|c|}
\hline Age group & Common pathogens & Empiric treatment & Intravenous dosing \\
\hline \multirow[t]{2}{*}{ Neonates <1-month-old } & \multirow[t]{2}{*}{$\begin{array}{l}\text { Streptococcus agalactiae, } \\
\text { Escherichia coli, Listeria } \\
\text { monocytogenes }\end{array}$} & \multirow[t]{2}{*}{$\begin{array}{l}\text { Amoxicillin/ampicillin/ } \\
\text { penicillin plus cefotaxime, or } \\
\text { amoxicillin/ampicillin plus an } \\
\text { aminoglycoside }\end{array}$} & $\begin{array}{l}\text { Age }<1 \text { week: cefotaxime } \\
50.0 \mathrm{mg} / \mathrm{kg} \text { q8H; ampicillin/ } \\
\text { amoxicillin } 50.0 \mathrm{mg} / \mathrm{kg} \mathrm{q} 8 \mathrm{H} \text {; } \\
\text { gentamicin } 2.5 \mathrm{mg} / \mathrm{kg} \mathrm{q} 12 \mathrm{H} \text {. }\end{array}$ \\
\hline & & & $\begin{array}{l}\text { Age 1-4 weeks: ampicillin } \\
50.0 \text { mg/kg q6H; } \\
\text { cefotaxime } 50.0 \text { mg/kg } \\
\text { q6-8H; gentamicin } 2.5 \text { mg/ } \\
\text { kg q8H; tobramycin } 2.5 \text { mg/ } \\
\text { kg q8H; amikacin } 10.0 \text { mg/ } \\
\text { kg q8H. }\end{array}$ \\
\hline 1 month to 18 years & $\begin{array}{l}\text { Streptococcus pneumoniae, } \\
\text { Neisseria meningitidis, } \\
\text { Haemophilus influenzae }\end{array}$ & $\begin{array}{l}\text { Cefotaxime or ceftriaxone } \\
\text { plus vancomycin or rifampin }\end{array}$ & $\begin{array}{l}\text { Vancomycin } 10-15 \mathrm{mg} / \\
\mathrm{kg} \text { q6H to achieve serum } \\
\text { trough concentrations of } \\
15-20 \mathrm{\mu g} / \mathrm{mL} \text {; rifampin } 10 \\
\mathrm{mg} / \mathrm{kg} \text { q12H up to } 600 \mathrm{mg} / \\
\text { day; cefotaxime } 75 \mathrm{mg} / \\
\mathrm{kg} \mathrm{q} 6-8 \mathrm{H} \text {; ceftriaxone } 50 \\
\mathrm{mg} / \mathrm{kg} \text { q12H (maximum } 2 \mathrm{~g} \\
\mathrm{q} 12 \mathrm{H} \text { ). }\end{array}$ \\
\hline Adults & $\begin{array}{l}\text { S. pneumoniae, } N \text {. } \\
\text { meningitidis }\end{array}$ & $\begin{array}{l}\text { Cefotaxime or ceftriaxone } \\
\text { plus vancomycin or rifampin }\end{array}$ & $\begin{array}{l}\text { Ceftriaxone } 2 \text { g q12H or } 4 \mathrm{~g} \\
\text { q24H; cefotaxime } 2 \mathrm{~g} \text { q4-6 } \\
\mathrm{H} \text {; vancomycin } 10-20 \mathrm{mg} / \\
\mathrm{kg} \text { q8- } 12 \mathrm{H} \text { to achieve serum } \\
\text { trough concentrations of } \\
15-2 \mathrm{Og} / \mathrm{mL} \text {; rifampin } 300 \\
\mathrm{mg} \mathrm{q} 12 \mathrm{H} \text {. }\end{array}$ \\
\hline $\begin{array}{l}\text { Elderly or risk of } \\
\text { immunocompromise }\end{array}$ & $\begin{array}{l}\text { S. pneumoniae, } \\
\text { N. meningitidis, } L \text {. } \\
\text { monocytogenes, } H \text {. } \\
\text { influenzae }\end{array}$ & $\begin{array}{l}\text { Cefotaxime or ceftriaxone } \\
\text { plus vancomycin or rifampin } \\
\text { plus amoxicillin/ampicillin/ } \\
\text { penicillin G }\end{array}$ & $\begin{array}{l}\text { Ceftriaxone } 2 \text { g q12H or } 4 \mathrm{~g} \\
\text { q24H; cefotaxime } 2 \text { g q4- } \\
6 \mathrm{H} \text {; vancomycin } 10-20 \text { mg/ } \\
\text { kg q8-12H to achieve serum } \\
\text { trough concentrations of } \\
\text { 15-20 } \mathrm{\mu g} / \mathrm{mL} \text {; rifampin } 300 \\
\text { mg q12h, amoxicillin, or } \\
\text { ampicillin } 2 \mathrm{~g} \text { q4H. }\end{array}$ \\
\hline
\end{tabular}

\section{Treatment}

Treatment of meningitis is typically initiated based on clinical suspicion or abnormal CSF cell counts/differential because CSF cultures results can be obtained within a day or two. Any patient with concern for sepsis or septic shock should be started on an empiric regimen of broad-spectrum antibiotics and antivirals even before performing the LP in order to not delay treatment. Management of severe sepsis and shock should follow current sepsis guidelines. ${ }^{21}$ ESCMID guidelines for empiric antibiotics based on age and common pathogens can be found in Table $2 .^{5}$
Adjunctive steroids should be considered in patients with suspected bacterial meningitis because animal studies have shown reduced inflammation, and thus decreased neurological sequelae, with their use. Morbidity secondary to hearing loss is a known neurological sequela in cases of severe bacterial meningitis. ${ }^{22}$ It is because of this that steroids are recommended to be given with the initial dose of antibiotics. Based on the Cochrane review by Brouwer et al.,22 there is no difference in mortality with steroid administration, but there is significant decrease in hearing loss and neurological sequelae. The evidence for a clear benefit from steroids is not as strong in the paediatric population. However, 
current guidelines do recommend administering steroids with the first dose of antibiotics when bacterial meningitis is suspected in paediatric patients..$^{23,24}$

Treatment for viral meningitis is largely supportive. Adults are often treated with acyclovir but currently there are no studies that show a significant benefit in meningitis.

\section{ENCEPHALITIS}

Encephalitis is a syndrome in which the brain parenchyma is invaded by a pathogen or microorganism and presents with encephalopathy and evidence of CNS inflammation. Encephalopathy is defined as any altered level of consciousness present for at least 24 hours. ${ }^{25}$ This includes lethargy, irritability, or a change in personality or behaviours. Evidence of CNS inflammation includes fever, focal neurological findings, seizures, CSF pleocytosis, electroencephalogram (EEG) abnormalities, and neuroimaging findings consistent with encephalitis. ${ }^{25}$ An important distinction is the CNS inflammation that is caused by the infection, which differentiates encephalitis from other causes of encephalopathy.

Each year there are approximately 6,000 cases of encephalitis requiring hospitalisation in the UK. ${ }^{26}$ Viruses are responsible for a vast majority, $20-50 \%$, of which HSV is the most prevalent. ${ }^{27,28}$ Of the cases remaining, close to one-half will have no identifiable cause..$^{27,29}$ In the past decade, antibody-mediated encephalitis caused by autoimmune or paraneoplastic processes has become the third most common type of encephalitis, responsible for as many as $20-30 \%$ of cases. ${ }^{28,30}$ Anti-NMDA receptor encephalitis is the most common autoimmune encephalitis, with antibodies against LGI1 (leucine-rich glioma inactivated 1 protein) being the second most prevalent. 30

On a worldwide basis, Japanese encephalitis has become a common pathogen, responsible for 30,000-50,000 cases of encephalitis annually. ${ }^{31}$ Eradication and control of Japanese encephalitis is important; while it primarily affects certain endemic areas, the population density in those regions often leads to high morbidity and mortality rates. $^{32}$ Since the eradication of polio, Japanese encephalitis is now at the forefront of international focus due to its long-term neurological sequelae and high mortality rates.

\section{Clinical Presentation}

Initial evaluation should focus on a detailed history and examination because early diagnosis and treatment improves outcomes and decreases long-term disability. Important components of the patient's history include recent travel, animal exposure and bites, vaccinations, contact with people who have been ill, recent illness, and occupation. It is also vital to consider the patient's demographics, season of presentation, and any local community pathogens.

Physical examination findings such as fever, mental status changes, neurological deficits, memory impairment, behaviour changes, seizures, and exanthems are all commonly seen in encephalitis. While some classic associations exist, the overlap in symptoms between the various causes of encephalitis as well as many other disease processes complicates the diagnostic process.

The most common of the viral encephalitis aetiologies is HSV, which accounts for $50-75 \%$ of cases. ${ }^{27}$ Studies comparing HSV to all other causes of encephalitis revealed that patients with HSV were likely to be older (88\% versus $64 \%$, respectively), febrile ( $80 \%$ versus $49 \%$, respectively), and experience gastrointestinal symptoms (37\% versus 19\%, respectively). ${ }^{33}$ They also found lower rates of ataxia and exanthems in the HSV group when compared with other causes of encephalitis. ${ }^{33}$ Given that HSV is more than likely to affect the temporal lobe, it is common to see olfactory hallucinations, personality changes, and psychosis, making it important to inquire about any underlying history of psychiatric diagnoses. ${ }^{28,34}$

Another cause of encephalitis that can often initially be misdiagnosed as a psychiatric disorder is anti-NMDA receptor encephalitis. This antibodymediated form of encephalitis typically presents with a vague influenza-like illness that, over the course of 1-2 weeks, progresses into altered mental status, paranoia, hallucinations, and bizarre behaviour. ${ }^{35}$ Ninety percent of patients are young females, and ovarian teratomas are present in $60 \%$ of these patients. ${ }^{35}$ 
Table 3: Infectious causes of encephalitis. ${ }^{27,28,30}$

\begin{tabular}{|c|c|}
\hline Viral & \\
\hline Herpesviridae & $\begin{array}{l}\text { Herpes simplex-1 (HSV-1/HHV1) } \\
\text { Herpes simplex-2 (HSV-2/HHV2) } \\
\text { Varicella zoster (HHV3) } \\
\text { Epstein-Barr (HHV4) } \\
\text { Human herpes-6 (HHV6) } \\
\text { Human herpes-7 (HHV7) }\end{array}$ \\
\hline Picornaviridae & $\begin{array}{l}\text { Enterovirus } 70 \\
\text { Enterovirus } 71 \\
\text { Poliovirus } \\
\text { Coxsackievirus }\end{array}$ \\
\hline Orthomyxoviridae & Influenza \\
\hline Paramyxoviridae & $\begin{array}{l}\text { Measles } \\
\text { Mumps }\end{array}$ \\
\hline Bunyaviridae & $\begin{array}{l}\text { La Crosse } \\
\text { Toscana } \\
\text { Jamestown Canyon } \\
\text { California encephalitis }\end{array}$ \\
\hline Flaviviridae & $\begin{array}{l}\text { West Nile } \\
\text { Dengue } \\
\text { Zika } \\
\text { Japanese encephalitis } \\
\text { Powassan } \\
\text { Saint Louis encephalitis }\end{array}$ \\
\hline Togaviridae & $\begin{array}{l}\text { Eastern equine encephalitis } \\
\text { Western equine encephalitis } \\
\text { Venezuelan equine encephalitis } \\
\text { Chikungunya }\end{array}$ \\
\hline Bacterial & $\begin{array}{l}\text { Bartonella henselae } \\
\text { Borrelia burgdorferi } \\
\text { Brucella spp. } \\
\text { Chlamydia pneumonia } \\
\text { Chlamydia psittacosaurus } \\
\text { Listeria monocytogenes } \\
\text { Mycobacterium tuberculosis } \\
\text { Mycobacterium pneumoniae } \\
\text { Pasteurella multocida } \\
\text { Streptococcus pyogenes } \\
\text { Streptococcus agalactiae } \\
\text { Tropheryma whipplei }\end{array}$ \\
\hline
\end{tabular}


Table 3 continued.

\begin{tabular}{|c|c|}
\hline \multirow{2}{*}{$\begin{array}{l}\text { Autoimmune } \\
\text { Antibody-mediated }\end{array}$} & \\
\hline & $\begin{array}{l}\text { NMDA } \\
\text { AMPAR } \\
\text { CASPR2 } \\
\text { D2R } \\
\text { DPPX } \\
\text { GABA }_{A} \text { receptor } \\
\text { GABA }_{B} \text { receptor } \\
\text { LGI1 } \\
\text { mGluR5 } \\
\text { Neurexin-3a }\end{array}$ \\
\hline Rickettsiae & $\begin{array}{l}\text { Anaplasma phagocytophilum } \\
\text { Coxiella burnetii } \\
\text { Ehrlichia chaffeensis } \\
\text { Rickettsia rickettsii } \\
\text { Rickettsia typhi }\end{array}$ \\
\hline Fungi & $\begin{array}{l}\text { Blastomyces dermatitidis } \\
\text { Coccidioides immitis } \\
\text { Cryptococcus spp. } \\
\text { Histoplasma capsulatum }\end{array}$ \\
\hline Protozoan & $\begin{array}{l}\text { Acanthamoeba spp. } \\
\text { Balamuthia mandrillaris } \\
\text { Baylisascaris procyonis } \\
\text { Naegleria fowleri }\end{array}$ \\
\hline
\end{tabular}

Autonomic instability is identified late in the disease course, with $76 \%$ of patients developing seizures and $88 \%$ experiencing decreased consciousness and akinesis. ${ }^{35}$

There are numerous additional causes of encephalitis including viral, bacterial, fungal, mycoplasma, Rickettsia, protozoan, and autoimmune. For the purpose of this review, the authors chose to focus on common pathogens that all clinicians should be familiar with in order to appropriately workup a patient presenting with suspected encephalitis. A more extensive list of causes of encephalitis can be found in Table 3.27,28,30

\section{Diagnosis}

Differentiating encephalitis from the many causes of encephalopathy can be very difficult because their clinical presentations are all similar, often leading to delays in diagnosis and treatment. Common mimics of encephalitis include conditions of a metabolic (hypoglycaemia, hyponatraemia, hepatic encephalopathy, toxins), inflammatory (vasculitis, autoimmune diseases), infectious (sepsis, bacterial meningitis, opportunistic infections), neoplastic, psychiatric, and stroke origin. ${ }^{29}$ Due to the overlap in symptomatology, evaluating for evidence of CNS inflammation is key to early diagnosis and treatment.

The major components of any encephalitis workup should include CSF analysis, neuroimaging, and EEG. All patients with suspected encephalitis should also undergo HIV testing because a positive result would significantly alter the differential diagnosis and workup. ${ }^{29}$ Additionally, it is important for providers to keep in mind the many encephalitis mimics and work diligently to rule out other causes. 
Many would argue the most important step in the evaluation of CNS inflammation is performing an emergency LP. As discussed prior, there are guidelines for when it is appropriate to delay LP for CT scan. However, every effort should be made to obtain CSF promptly because it is key to guiding management and confirming the diagnosis. In all cases, CSF studies should include cell count and differential, protein, glucose, Gram staining, cultures, cryptococcal antigen test/ India ink staining, venereal disease research laboratory test, and PCR for HSV-1, HSV-2, VZV, and enterovirus. Additional testing may be required based on demographics, occupational, and environmental exposures. For this reason, it is recommended to send additional CSF to the lab in case more specific testing needs to be added as the workup evolves. Recently, nextgeneration sequencing has shown promise in the identification of cases of encephalitis with unknown aetiology; however, it is outside of the scope of this review article.

CSF analysis in viral encephalitis typically presents with a lymphocytic pleocytosis. However, early on in viral infections, neutrophils can predominate. Protein will be mildly elevated with a normal glucose (Table 1). HSV-1 and HSV-2 PCR has a sensitivity of $96 \%$ and specificity of $99 \%$, however it can be negative early on in the disease progress. $^{36,37}$ If there is high clinical suspicion for HSV, many sources recommend repeat CSF analysis on subsequent days. . $^{28,29,36,37}$ In regard to anti-NMDA receptor encephalitis, antiglutamate receptor NMDAR1 and antiglutamate receptor NMDAR2 antibodies are pathognomonic for the diagnosis. 38

The preferred neuroimaging study in encephalitis is MRI because it has both a better sensitivity and specificity than $\mathrm{CT}^{28,29,36}$ In reality, most patients will first undergo $\mathrm{CT}$ brain imaging as part of their initial workup to exclude other causes. However, MRI abnormalities can clue care providers into specific aetiologies based on imaging patterns, characteristics, and locations of abnormalities. ${ }^{28}$ One of the best examples of this is HSV encephalitis, in which an abnormal MRI is seen in up to $90 \%$ of cases. ${ }^{29}$ Findings consistent with HSV include asymmetric hyperintense signal on T2-weighted and fluid-attenuated inversion recovery sequences in the temporal, orbitofrontal, or insular regions. ${ }^{37}$ If there is a high suspicion for antibody-mediated encephalitis, further imaging to assess for a paraneoplastic process will be required. ${ }^{29}$ In the case of anti-NMDA receptor encephalitis, due to the high association with ovarian teratoma, it is recommended to obtain a pelvic ultrasound or $\mathrm{CT}^{35}$

EEG is commonly recommended in the workup for encephalitis; however, EEG findings alone are nondiagnostic. ${ }^{29,36}$ Signs of encephalopathic change can help guide further workup as well as rule out encephalitis mimics such as psychiatric disease. HSV has been associated with generalised slowing, periodic discharges, and electrographic seizures. ${ }^{36,37}$ Case reports of anti-NMDA receptor encephalitis have also shown that $80 \%$ of patients have generalised slowing on EEG and $50 \%$ have epileptic activity. ${ }^{28}$

\section{Treatment}

Similar to meningitis, treatment for encephalitis is initiated based on clinical suspicion because CSF testing for specific aetiologies will not yield same-day results. In addition to the disease-specific treatment, close monitoring for hypoglycaemia, increased intracranial pressure, and seizures is important. In all patients with encephalitis, it is recommended to start empiric intravenous acyclovir (Infectious Disease Society of America [IDSA] A-level recommendation) because it has a low side-effect profile and has been shown to reduce mortality in HSV encephalitis from $70 \%$ to $10-20 \%{ }^{29,39}$ If the patient is HSV positive, acyclovir should be continued for a minimum of 2 weeks, at which time most sources recommend repeat LP to guide further management. $28,36,37$ There is a lack of evidence to support the use of glucocorticoids in HSV, Epstein-Barr virus, or VZV encephalitis. ${ }^{39}$ Treatment for anti-NMDA receptor encephalitis is immunotherapy and early tumour removal in the setting of paraneoplastic cases. Immunotherapy includes high-dose corticosteroids, intravenous immunoglobulin, and exchange transfusion. ${ }^{29}$

\section{Prevention}

Preventative measures

against meningoencephalitis are vital in preventing epidemics. This is particularly true for viral aetiologies due to a lack of efficacious treatments for most neurotropic agents. ${ }^{27}$ Prevention methods largely centre around adhering to vaccination guidelines, proper hygiene, and distancing, as with any infection. In infections 
for which N. meningitidis or Hib is suspected, prophylactic antibiotic treatment of close contacts and exposed healthcare workers is key to prevention as well.

\section{Opportunistic infections}

Opportunistic infections of the CNS are most common in individuals with significant immunocompromise. Common scenarios include AIDS, post-transplant, and immunodeficiency syndromes. Most pathogens are inhaled and only cause systemic disease in the setting of significant immunosuppression.

\section{Cryptococcal Meningitis}

Cryptococcal meningitis is the most common cause of meningitis among those infected with $\mathrm{HIV}^{40}$ It is also one of the most common fungal infections in the post-transplant period. ${ }^{41}$ Approximately $7-15 \%$ of patients with AIDS become infected with cryptococcus and it is responsible for up to one-fifth of AIDS-related mortality worldwide. ${ }^{42}$

Diagnosis requires a detailed physical exam and high index of suspicion. Due to underlying immunocompromise, classic symptoms such as fever and nuchal rigidity are not common. Rather, the most common symptoms are headache, altered mental status, and vision changes. ${ }^{43}$

The diagnostic pathway is similar to that described above, but it is important to measure an opening pressure when performing the LP, especially if there are clinical signs of increased intracranial pressure. CSF antigen testing is the gold standard for confirming diagnosis. The India ink stain has been studied as a useful screening test, especially in resource poor areas. However, it lacks specificity to serve as a confirmatory test (sensitivity: 90\%; specificity: 50-75\%). ${ }^{44}$ Treatment consists of lowering intracranial pressure, if elevated, and antifungals. Specific agents should be chosen in consultation with local infectious disease guidelines.

\section{Toxoplasmosis}

Toxoplasmosis results from a parasitic infection of brain parenchyma. CNS infection typically occurs as a result of the reactivation of an old
CNS lesion or haematogenous spread from an active infection. It is usually spread by consuming undercooked food that is contaminated with cysts; cat faeces is another common source. ${ }^{45}$ The epidemiology of this disease varies greatly based on availability of antiretroviral treatment because it primarily affects patients with AIDS with CD4+ counts less than 200 cells $/ \mathrm{mm}^{3} .45$ Clinical presentation again varies greatly due to underlying immunocompromise, but special note must be made of any movement disorder because toxoplasmosis has a propensity to invade basal ganglia. ${ }^{46}$ Diagnosis differs from that of other CNS infections because of the tendency of toxoplasmosis to form ring-enhancing lesions and potentially increase intracranial pressure. LP should not be performed if there are any clinical signs of increased intracranial pressure. Definitive diagnosis is made with serological testing. Rapid PCR showed a sensitivity of $83.3 \%$ and specificity of $95.7 \% .{ }^{47} \mathrm{CT}$ and $\mathrm{MRI}$ imaging with contrast can also reveal cystic lesions in the brain parenchyma. Similarly, treatment consists of addressing intracranial pressure, if elevated, as well as broad spectrum antibiotics. Agents should be selected in conjunction with infectious disease input.

\section{CONCLUSION}

Infections of the CNS require strong clinical suspicion and prompt workup to improve morbidity and mortality. Empiric treatment should not be delayed by imaging. However, it is important to understand that neuroimaging should precede LP in patients with focal neurological deficits, depressed Glasgow coma score, and clinical signs of increased intracranial pressure. Treatment should be initiated with broad spectrum antibiotics and tapered as possible. Suspected cases of encephalitis should be covered empirically with antivirals. Steroids have also shown benefit in improving neurological sequelae as well as hearing loss in the setting of meningitis; however, are not recommended in cases of viral encephalitis. Of special note are opportunistic infections of CNS, which must be considered in patients with significant immunocompromise. 


\section{References}

1. Abott $\mathrm{NJ}$ et al. Astrocyte-endothelial interactions at the blood-brain barrier. Nat Rev Neurosci. 2006;7(1):41-53.

2. Von Tell D et al. Pericytes and vascular stability. Exp Cell Res. 2006;312(5):623 9.

3. Frosch MP et al., "The Central Nervous System", Kumar V et al. (eds), Robbins and Cotran Pathologic Mechanisms of Disease $9^{\text {th }}$ Edition (2014), Philadelphia: Elsevier Saunders, pp. 1272-4

4. Tanski ME et al., "Central Nervous System and Spinal Infections", Tintinalli JE et al. (eds), Tintinalli's emergency medicine: a comprehensive study guide $8^{\text {th }}$ Edition (2011), New York: McGrawHill, pp. 1192-5.

5. van de Beek D et al. ESCMID guideline: diagnosis and treatment of acute bacterial meningitis. Clin Microb Infect. 2016;22:S37-62

6. Suga $S$ et al. A nationwide populationbased surveillance of invasive Haemophilus influenzae diseases in children after the introduction of the Haemophilus influenzae Type b vaccine in Japan. Vaccine. 2018;36(38):567884.

7. von Gottberg A et al. Invasive disease due to Haemophilus influenzae serotype $b$ ten years after routine vaccination, South Africa, 2003-2009. Vaccine. 2012;30(3):565-71.

8. Edmond $\mathrm{K}$ et al. Global and regional risk of disabling sequelae from bacterial meningitis: a systematic review and meta-analysis. Lancet Infect Dis. 2010;10(5):317-28

9. Desmond RA et al. Enteroviral meningitis: natural history and outcome of pleconaril therapy. Antimicrob Agents Chemother. 2006;50(7):240914.

10. Attia J, Hatala R. The rational clinical examination. Does this adult patient have acute meningitis? JAMA 1999;282(2):175-81.

11. Ward MA et al. Josef Brudzinski and Vladimir Mikhailovich Kernig: signs for diagnosing meningitis. Clin Med Res. 2010;8(1):13-7.

12. Tamune $\mathrm{H}$ et al. Absence of jolt accentuation of headache cannot accurately rule out meningitis in adults. Am J Emerg Med. 2103:31(11):1601-4.

13. Nakao JH et al. Jolt accentuation of headache and other clinical signs: poor predictors of meningitis in adults. Am J Emerg Med. 2014;32(1)24-8.

14. Michael B et al. Effect of delayed lumbar punctures on the diagnosis of acute bacterial meningitis in adults. Emerg Med J. 2010;27(6):433-8.

15. Agueda $\mathrm{S}$ et al. Prediction of bacterial meningitis based on cerebrospinal fluid pleocytosis in children. Braz J Infect Dis. 2013;17(4)401-4.

16. Griffiths MJ et al. Management of acute meningitis. Clin Med. 2018;18(2):164-9.

17. Mackay IM. Real-time PCR in the microbiology laboratory. Clin Microbiol Infect. 2004;10:190-212.

18. Leber AL et al. Multicenter evaluation of biofire filmarray meningitis/ encephalitis panel for detection of bacteria, viruses, and yeast in cerebrospinal fluid specimens. J Clin Microbiol. 2016;54(9):2251-61.

19. Lyons TW et al. Impact of in-hospital enteroviral polymerase chain reaction testing on the clinical management of children with meningitis. J Hosp Med. 2012;7(7):517-20.

20. Hagen A et al. Comparison of antibiotic and acyclovir usage before and after the implementation of an on-site FilmArray meningitis/encephalitis panel in an academic tertiary pediatric hospital: a retrospective observational study. BMC Pediatri. 2020;20(1):56.

21. Rhodes A et al. Surviving Sepsis Campaign: international guidelines for management of sepsis and septic shock: 2016. Intensive Care Med. 2017;43(3):304-77

22. Brouwer $M C$ et al. Corticosteroids for acute bacterial meningitis. Cochrane Database Syst Rev. 2015;(9):CD004405

23. Swanson D. Meningitis. Pediatr Rev. 2015;36(12):514-24

24. Kimberlin DW et al., "Pneumococca infections", Long SS et al. (eds), Red Book: 2018 Report of the Committee on Infectious Diseases (2018), Itasca: American Academy of Pediatrics, pp. 639.

25. Granerod J et al. Causes of encephalitis and differences in their clinical presentations in England: a multicentre, population-based prospective study. Lancet Infect Dis. 2010;10:834-44.

26. Granerod J et al. New estimates of incidence of encephalitis in England. Emerg Infect Dis. 2013;19:1455-62.

27. Tyler KL. Acute viral encephalitis. N Engl J Med. 2018;379(6):557-66

28. Venkatesan A et al. Acute encephaliti in immunocompetent adults. Lancet. 2019;393(10172):702-16.

29. Ellul M, Solomon T. Acute encephalitis - diagnosis and management. Clin Med. 2018;18(2)155-9.

30. Dalmau J, Graus F. Antibodymediated encephalitis. N Engl J Med. 2018;378(9):840-51.

31. Tyler K. Emerging viral infections of the central nervous system. Arch Neurol. 2009;66(8):939-48.

32. Solomon T. Control of Japanese encephalitis - within our grasp? N Engl J Med. 2006;355:869-71.

33. Chow FC et al. Use of clinical and neuroimaging characteristics to distinguish temporal lobe herpes simplex encephalitis from its mimics. Clin Infect Dis. 2015;60:1377-83.

34. Dorsett M, Liang SY. Diagnosis and treatment of central nervous system infections in the emergency department. Emerg Med Clin North Am. 2016;34(4):917-42.

35. Dalmau J et al. Paraneoplastic anti-N-methyl-D-aspartate receptor encephalitis associated with ovarian teratoma. Ann Neurol. 2007;61:25-36.

36. Bradshaw MJ, Venkatesan A. Herpes simplex virus-1 encephalitis in adults: pathophysiology, diagnosis, and management. Neurotherapeutics. 2016;13(3):493-508

37. Rabinstein AA. Herpes virus encephalitis in adults: current knowledge and old myths. Neurol Clin. 2017;35(4):695-705.

38. Wandinger KP et al. Anti-NMDA receptor encephalitis: a severe multistage, treatable disorder presenting with psychosis. J Neuroimmunol. 2011;231:86-91.

39. Tunkel AR et al. The management of encephalitis: clinical practice guidelines by the Infectious Disease Society of America. Clin Infect Dis. 2008;47:303 27.

40. Saylor D. Neurologic complications of human immunodeficiency virus infection. Continuum. 2018;24(5):1397421.

41. Sun $\mathrm{HY}$ et al. Unrecognized pretransplant and donor-derived cryptococcal disease in organ transplant recipients. Clin Infect Dis. 2010;51(9):1062-9.

42. Rajasingham R et al. Global burden of disease of HIV-associated cryptococcal meningitis: an updated analysis. Lancet Infect Dis. 2017;17(8):873-81.

43. Perfect JR, Bicanic T. Cryptococcosis diagnosis and treatment: what do we know now. Fungal Genet Biol. 2015;78:49-54.

44. YMC Coovadia et al. A comparative evaluation of the Gram stain and India ink stain for the rapid diagnosis of cryptococcal meningitis in HIV infected patients in Durban. S Afr J Infect Dis. 2015;30(2):61-3.

45. Robert-Gangneux F, Dardé ML. Epidemiology of and diagnostic strategies for toxoplasmosis. Clin Microbiol Rev. 2012;25(2):264-96.

46. Smith $A B$ et al. From the archives of the AFIP: central nervous system infections associated with human immunodeficiency virus infection: radiologic-pathologic correlation. Radiographics. 2008;28(7):2033-58.

47. Alfonso $\mathrm{Y}$ et al. Molecular diagnosis of Toxoplasma gondii infection in cerebrospinal fluid from AIDS patients. Cerebrospinal Fluid Res. 2009;6:2. 